CHAPTER $X$

\title{
Bringing Materiality into Thinking About Digital Literacy
}

Theories and Practices of Critical Education in a Digital Age

\author{
Holger Pötzsch \\ UiT - The Arctic University of Norway
}

\section{Keywords}

Critical digital literacies, digital technologies, materiality, practice, Wikipedia, Phone Story, digital capitalism

\section{Introduction}

This chapter makes a critical intervention in studies and practices of digital literacy. Drawing upon the insight that artifacts do have politics (Winner 1980 ) and that humans and objects continuously co-constitute and shape one another's agential capacities (Orlikowski 2007), I argue that to become digitally literate also implies an awareness of digital technologies' material dimension, i.e. their technological affordances, economic embedding, and societal, environmental as well as embodied effects and repercussions. After a brief walk-through of key advances in thinking about literacy, the chapter homes inn on the notion of critical digital literacies to conceptually back the further inquiry.

I define critical digital literacies as the knowledges, skills, and competences necessary to see the use and implications of digital technologies in the widest possible context. Pointing beyond such issues as quantifiable learning outcomes, possible obstacles to rapid uptake in schools, or potentials for increased inclusion and empowerment through educational technologies, a critical materialist approach also directs attention to unintended economic, social and environmental ramifications, focuses on questions of surveillance and subject formation 
in and through technology, and offers concrete alternatives to hegemonic tools and practices. After having outlined such key aspects, I provide a series of concrete recommendations on how critical literacies can be fostered in the contemporary classroom both with and without access to digital devices.

The chapter offers an overview over 1) free and privacy-enhancing software applications as alternatives to corporate products, 2) ideas and resources for classroom sessions with a critical angel, and 3 ) civil society organizations that might help teachers and learners with acquiring technical and other skills. In addition, I present concrete classroom activities that make use of the presented resources with particular focus on the free online encyclopedia Wikipedia and the critical mobile game Phone Story.

\section{Towards an Understanding of Critical Digital Literacy}

During much of the $20^{\text {th }}$ century the gradual emergence of various 'new' media technologies such as film, radio, television, video, DVDs, and ultimately computational and digital media have posed new challenges for thinking, teaching, and practicing literacy (Mills 2015). An earlier limitation of focus on the acquisition and competent use of spoken and written language was increasingly supplemented with attention to the requirements, problems, and opportunities of technical media and their implications for teaching, learning, and life. A series of studies devised concepts such as new media literacy or multi-modal literacy to describe complex sets of semiotic resources enabling 'speakers' to engage in situated practices of meaning making across multiple modalities and layers of mediation (Cazden et al. 1996; Kress and van Leuwen 2001; Kress 2003).

Other scholars followed a tradition of media critique. Often subsumed under the header of critical media literacy, Buckingham (1993a\&b), Kellner (1995), Janks (2009), Hagood (2009), Luke (2012), and others devised strategies and tools to understand, critique, and efficiently counter complex messages and ideological biases disseminated via 'new' audio-visual media such as film, television, and later video games and social media. Drawing upon techniques derived from post-structuralism, post-colonial, gender and critical race studies, as well as cultural and Marxist approaches, they traced power relations and ideology throughout communication processes - from production via textual structures to 
reception and reproduction (see Hall 1977). As a consequence, these approaches moved focus from a supposedly passive audience exposed to ideological interpellation to active and situated semiotic practices of reading, re-reading, appropriation, and production in contingent discursive and other contexts. Many of these critical approaches perceived of digital network technologies - the early Internet first and foremost - as a genuine opportunity for a more even distribution of power between 'producers' and 'receivers' of mass mediated messages (Buckingham 2003, 2006; Jenkins 2006; Livingstone 2012; Janks 2014).

Drawing upon the work of Paolo Freire (1970), Allen Luke (2012) argues that to become literate means more than preparing oneself for an efficient functioning within given societal and economic frames. Rather, he states, education should be participatory and openly normative. The aim should be to empower people to use a variety of media to actively interrogate received frames, subvert them if necessary, and replace them with more inclusive and just alternatives where possible. As a result, not only the critical analysis of and resistance to biased media content is key to critical literacies, but so is the ability to freely access, produce, and share alternative content. Concluding his argument, Luke asserts that recent developments in both technological and socio-economic areas "require a new vocabulary" (p. 9) enabling us to properly understand, appropriate and, if need be, oppose new digital technologies - a specifically digital form of critical literacy (for an integration of Luke's ideas into current curricula, see Hinrichsen and Coombs 2014).

According to Lankshear and Knobel (2015), the most crucial flaws of "mainstream approaches" (p. 10) to digital literacy are that they 1) tend to reduce the term to merely technical information transfer thereby distorting the socio-cultural aspects of communication as meaningmaking in a variety of contexts, and 2) that they conceive of literacy as a singular and autonomous 'thing' - a set of abstracted skills and tools that can be accurately described and tested and that learners either have or have not. ${ }^{1}$ Thereby, the authors argue, mainstream definitions disregard the multiple nature of literacy as "a function of social practice, social context, and discourse" (p. 13), before they offer a socio-cultural

\footnotetext{
${ }^{1}$ For such a mainstream approach, see for instance the European Commission's DigiComp framework (Vuorikari et al. 2016).
} 
understanding of literacy as an alternative that takes contingencies of use and appropriation of digital technologies into account.

Operationalizing such extended perspectives, Ávila and Zacher Pandya (2013) advance their understanding of critical literacies as situated social praxis. Drawing upon Luke's (2012) work among others, they combine design-oriented advances in a multi-literacies tradition with classical approaches aiming at ideological critique of media content and contexts of production. Focusing the discussion on digital technologies, they define critical digital literacy as "those skills and practices that lead to the creation of digital texts that interrogate the world [and that] allow and foster the interrogation of digital multimedia texts" (p. 3). One key element in their praxis-oriented thinking is the empowerment of disenfranchised groups and individuals by means of available new technologies (p. 4-5) - a processes that, according to them, often entails a tricky redistribution of roles in particular in educational settings with pupils suddenly taking on the role of experts (at least as long as practical user skills are concerned).

This chapter acknowledges the importance of Ávila and Zacher Pandya's (2013) approach, but intends to push the limits of what critical digital literacy entails even further. As Avila and Zacher Pandya acknowledge, digital tools are not in themselves empowering and even though I am sympathetic to their idea of "letting students teach us, or each other" ( $p$. 6 ; emphasis in original) and that we should encourage them to "forge their own paths to authority" (ibid.), these assertions appear at times somewhat oblivious of the power structures that pre-dispose both design and use of most available digital technologies. What is lacking, or underemphasized, is critical attention to how digital capitalism works; how economic relations of production, commodification, and exploitation predispose technological affordances to mold subjectivities and practices in the name of specific interests and a received status quo. In the words of Santo (2013, p.199) capitalist and other agendas are "implicit in the very design of [...] participatory tools" we attempt to use in the name of empowerment and liberation (see also Barassi 2016, Fenton 2016, and Pötzsch 2018).

Of course, I am not the first to suggest such a widened frame for critical digital literacies. Luciana Pangrazio (2016; see also Golden 2017 and Bigum and Rowan 2015), for instance, criticizes digital design models of literacy associated with the work of Kress (2003), Jenkins (2006) and 
others as celebrating "notions of individual agency" and as not involving "a critique of [...] issues such as the ownership of digital media platforms or their governance" (p. 167). As such, she concludes, many approaches leave "the underlying ideology of the digital contexts largely unquestioned" (p. 167). As an alternative, Pangrazio develops what she terms "critical digital design" that tries to overcome what she perceives as a received division in the field between attempts to direct focus at critical consumption and those interested in facilitating creative and empowering responses (see also Santo 2013). Her praxis-focused critical digital literacy approach aims at taking seriously the experiences and practices of individual users without however losing wider structural concerns out of sight. By these means individual expertise with available technologies can be appropriated for progressive purposes while at the same time retaining a critical distance to these same technologies' affordances and their embedding in systems of hegemony and oppression. Collective concerns as such become guiding lights for individual practices and technical mastery gains a critical focus.

\section{Widening the Frame: Critically Engaging Digital Capitalism}

Pangrazio's (2016) framework of critical digital design is crucial for the ideas developed in this chapter. However, she remains somewhat unclear about what exactly the questioning of an "underlying ideology of the digital contexts" (p. 167) means. It certainly implies that we should not only learn with or through, but also about technology (Buckingham 2006, p. 21), and that steps toward empowerment through media can only be realized as empowerment in relation to media (Santo 2013, p. 199). As Minna Saariketo $(2014,32)$ puts it, critical technology education needs to consider "how the digital society functions and whose interests steer it". In this respect, capitalism emerges as a veritable "elephant in the room" (Hoechsmann and Poyntz 2012, p. 162) in much thinking about literacies relevant for a digital age (see also Jones 2016).

As I have suggested elsewhere (Pötzsch 2016, 2017, 2018, 2019; see also Hoechsmann and Poyntz 2012, Golden 2017, Fuchs 2017, and others), digital technologies have a material dimension that needs to be taken seriously in attempts to properly understand, appropriate, challenge, and possibly subvert the ways these technologies operate in given socioeconomic and political contexts. For a widening of the conceptual frame of critical digital literacies, issues such as material infrastructure, energy consumption, working conditions, resource extraction, waste 
management, and embodied effects connected to the digital economy become important elements that need to be taken into consideration.

The current rapid growth of the digital economy leaves increasingly problematic societal and ecological footprints (Maxwell and Miller 2012; Pötzsch 2016; Qiu 2016; Fuchs 2017). The often-presumed affordability of apparently inexpensive digital devices and applications merely redistributes costs in a familiar pattern where (again) the global South and disenfranchised groups in the North are forced to bear the brunt of negative impacts regarding ecological degradation and economic exploitation. To make digital technologies affordable enough to enable inclusion into virtually every household and educational institution in the global North (while at the same time ensuring massive profits), we implicitly accept, reproduce, and intensify severely negative conditions elsewhere. Ecological degradation due to underregulated resource extraction and waste disposal, poor working conditions, lack of basic safety regulations, absence of health insurance or unemployment benefits, low wages, slavery, child labour, and other factors are the rule rather than the exception in contemporary digital capitalism (Maxwell and Miller 2012; Qui 2016; Global E-Waste Monitor 2017; Chinese Labour Watch 2018).

Exploitation, however, does not stop there. In thinking critically about digital literacy, we have to take seriously and understand how contemporary commercial giants such as Alphabet, Facebook, Microsoft, Amazon, Alibaba, Tencent, and others manage human attention and mold our preferences and desires through the gathering and commodification of massive amounts of user data. The business model of offering apparently free or cheap services and products in exchange for access to data lies at the core what Zuboff (2019) and Fuchs (20112a\&b, 2017), among many others, have referred to as global surveillance capitalism - a form of rule and governance that tacitly molds allegedly empowered participants into docile consumer profiles (see also Gehl 2014; Harcourt 2015; Golden 2017; Pötzsch 2018). According to Schäfer (2011) perceiving of "increased user activity [enabled by digital domains] as a fundamental shift in power structures" is an intellectual short cut (p.13) leading to the "myopic idea that participation by many users somehow equals democracy" (p. 45).

A detailed understanding of the economic and political conditions as well as the often-unintended detrimental effects of new technologies is a 
requirement for their politically progressive appropriation and reappropriation in educational settings and beyond. The material aspects highlighted above are important elements of a critical notion of digital literacy that is aimed at facilitating the development of sustainable, empowering, and liberating practices in the context of contemporary digital capitalism.

\section{Practices of Critical Digital Literacies}

Digital technologies have come to our classrooms to stay. Laptops, tablets, educational apps and platforms, MOOCs, learning analytics, and individualized learning management systems increasingly become a norm rather than an exception in contemporary education (Jones 2016; Golden 2017; Lynch 2017; Williamson 2016, 2017). As all digital technologies, also their educational variants always operate in context and are therefore characterized by ambiguities and contingencies. On the one hand commercial educational software and learning analytics applications promise cheap and efficient support to overburdened schools and teachers and claim to enable better learning and increased participation of previously marginalized groups. On the other hand, their intrinsic logics are often based on reductive understandings of education and human nature, sneak a behavioristic model of learning into established school practices, devalue experiences of teachers, tacitly privilege the optimization of quantifiable human capital, and remain opaque about privacy concerns, data gathering practices, and the ideological biases coded into the software (for thorough accounts of such factors, see Selwyn (2016), Jones (2016), Bayne (2015), Edwards (2015), Williamson (2015, 2017), Lindh and Nolin (2016), Golden (2017), Lynch (2017), and Simanowski (2018) among others). In particular, performative effects of adaptive learning and analytics software that become co-constitutive of the very learner identities and practices they purport to merely assess and describe merit continued critical attention (Edwards 2015; Williamson 2016, 2017; Golden 2017).

A series of critical advances in the field of literacies studies have focused on such and similar factors and have developed useful terminologies to grasp their rapidly moving target. Golden (2017) and Lynch (2017) propose the term sub-screenic literacies to bring insights from critical software studies (see Kitchin and Dodge 2011) to research on current teaching and learning, Pangrazio and Selwyn (2019) opt for personal data literacies to sensitize school owners, teachers, and learners for the data 
gathering and commodification strategies by state and commercial actors, Gray, Gerlitz and Bounegru (2018) deploy the concept of data infrastructure literacy to show that knowledge about physical network architectures is an important component of contemporary education aimed at furthering capacities to resist and reverse-engineer received technologies (see also Gehl 2014), while Santo (2013) deploys the term hacker literacies to account for the importance of both critical thinking and technological expertise for the appropriation and re-appropriation of digital applications and devices from below.

Important for all these approaches is a combination of knowledge about the structures and complex (and often-detrimental) implications and effects of digital capitalism with technical expertise and the ability to adopt, change, reverse-engineer and, if necessary, resist and discard new technologies in educational settings and beyond. All these advances offer valuable ideas for new educational practices aimed at conveying critical literacies for the sake of empowerment and liberation in the sense of Freire (1970), Luke (2012), and others. This chapter is deeply indebted to their endeavors.

\section{Application Matters: Non-Commercial Alternatives}

One fundamental aspect of engaging contemporary digital capitalism in and through education is to critically interrogate the technological affordances, costs, and implications of available devices with the objective og identifying affordable alternatives that serve their assigned purposes while at the same time refraining from surveilling and commodifying user data and identities.

Due to immense costs and logistical requirements, hardware manufacturing and distribution is almost entirely organized within a capitalist system. Attempts to break out of this received logic such as the development of the fair-trade smart phone Fairphone are still organized within the overarching patterns of digital capitalism. Even though, in this case, profit-rates are slashed for the sake of offering better wages, improved working conditions, and more control for users (Qiu 2016), the price, affordances, and further development of the product are still predominantly dictated by market logics and economic base-lines rather than political considerations. Therefore, few affordable alternatives to corporate hardware are available for use in the digital classroom today. In terms of software, however, there are more alternatives to choose 
from and the very ability to select proper applications for use becomes a matter of critical digital literacy.

Based on the work of Marisol Sandoval and Christian Fuchs (2010) and Robert Gehl (2015), a basic distinction between software applications can be made along the following lines; 1 ) commercial products offered a) for payment, b) for access to user data (personal and/or aggregated) or c) as free trials, and 2) non-commercial alternatives a) as free open source software (FOSS) developed and updated by volunteers, b) as products financed through donations, or c) as hacked and re-appropriated commercial software. In the following, I will mostly focus non-commercial solutions in the categories $2 \mathrm{a}$ and $\mathrm{b}$. Due to legal concerns, category $2 \mathrm{c}-$ hacked software - cannot be recommended for usage in formal educational settings even though the very ability to hack has to be considered a key aspect of critical digital literacies (Santo 2013).

To ensure necessary profits, commercial software production is dominated by inevitable economic considerations that, in the end, will trump other concerns. In the context of educational software, this means that often-postulated aims of improving learning, connecting people, or bringing technology to the poor are in essence the result of marketing strategies aimed at pitching particular products to public funding bodies, schools, or individual learners for the sake of increasing market shares and financial revenues. As a result, the availability of commercial educational software in schools and universities either requires massive public investments that could otherwise have been used for alternative purposes (such as hiring more teachers), or implies the often-tacit acceptance of massive data-gathering and profiling of users (mind here the distinction between personal information that is usually protected through terms-of-service agreements and aggregated user data that is usually open for commodification also in educational software; see Lindh and Nolin 2016). In addition, pushes for increased efficiency in education lead to a gradual privileging of easily quantifiable methods of assessment and evaluation through largely automated and adaptive systems that threaten to reduce education to the manufacturing of commodifiable human capital tailored to the requirements of current labor markets (Williamson 2016; Golden 2017; Simanowski 2018).

Using commercial products in education can lead to important results and can entail benefits for certain groups or progressive political projects. At an underlying level, however, the prescribed 'solutions' are bent on 
reproducing and reinforcing given relations of power (Sandoval \& Fuchs 2010, Gehl and Synder-Yuly 2016, Treré 2016, 2018). Non-commercial alternatives, on the other hand, often struggle with issues such as the selfexploitation of idealists and activists, a lack of necessary funding for maintenance, updates and support, problems with buy-outs or compatibility, as well as the challenge of attracting enough users to create a critical mass (see Gehl 2015, Treré 2016, and Fenton 2016). The free labour (Terranova 2000) put into the development of genuine FOSS applications is often recuperated by commercial actors in complex global "labour circuits" (Qiu, Gregg and Crawford 2014) that exploit non-profit collaborative and creative production for economic purposes. It is important that such aspects are sufficiently considered when selecting applications for use in critical digital literacies classrooms.

\section{Practicing Critical Literacies with Non-Commercial Software}

In this section, I firstly introduce a series of freely available applications that can be used in education to help individual users to secure their privacy online. Free and untraced access to information and the ability to prevent both state, private, and peer-to-peer surveillance are fundamental aspects of democratic life. Therefore, knowledge about applications facilitating such needs are important aspects of critical digital literacies - as is the awareness that, regardless one's technical expertise, $100 \%$ anonymity online is virtually impossible to achieve.

On the Internet, all activities are routinely surveilled by a plethora of commercial, state, and private actors (Andrejevic 2007, Gehl 2014, Fuchs 2017, Zuboff 2019). Normal browsers such as the commercial Chrome, Safari and Internet Explorer, or the non-commercial variant Firefox, among others, do not prevent data gathering strategies by default. Therefore, to navigate more freely in today's "digital enclosure" (Andrejevic 2007, p. 2), users can install a series of free add-ons in their preferred browsers or migrate to the protected yet somewhat slower Tor browser.

Important add-ons can be installed on e.g. Firefox through a few clicks and operate in the background. Available resources include httpseverywhere that defaults all web traffic to an encrypted format, various add-blockers that create default opt-in solutions for all online advertising, Facebook and Google Container that confine surveillance by these actors to single tabs, and Privacy Badger that protects user data against a variety of 
actors. The introduction of these and similar tools in class can be combined with exercises aimed at sensitizing learners for the extent of knowledge commercial actors already have acquired about our digital and physical lives. For a simple test aimed at revealing the immense amount of browsing, location, and connection data collected by Facebook and Google, see the tools offered in The Guardian (Curran 2018) that can form the basis for an easily accessible learner-driven exploration of one another's digital trails.

To ensure a higher degree of anonymity online, The Onion Router (Tor) can be downloaded for free and installed in a simple process. Tor constitutes a good alternative to commercial browsers as it does not track web traffic and hides users' identities and IP addresses ${ }^{2}$ as long as log-ins at sites such as YouTube, Facebook, TikTok, among many others are avoided and users refrain from employing bit-torrent or similar technologies. ${ }^{3}$ It is important to note that LAN administrators, certain Internet routers, and providers of Virtual Private Networks (VPNs) still will be able to log traffic and supply this information to other parties. Note also that the use of Tor is prohibited in countries such as Turkey, China, or Iran. Charges that the Tor browser facilitates criminal conduct and protects illegal activities online have been debunked among other things by showing that illicit practices have been unavoidable by-products of Internet use from the very beginning and are equally wide-spread on the clear web as on its dark counterpart (see for instance Gehl 2018).

Recently, there has been mounting evidence pointing to a fundamental compromising of Tor anonymization features by US security agencies (see for instance Gellman, Timberg and Rich 2013; Taylor 2019). This does not infringe upon Tor's capacity to prevent regular surveillance by peers or commercial actors, but severely decreases the browser's use value for political activism, investigative journalism, or human rights advocacy critical to US government interests. In such cases it is therefore advised to combine the use of Tor with trusted VPN providers who encrypt all web traffic and channel it through their own servers without logging or sharing

\footnotetext{
${ }^{2}$ IP addresses uniquely identify every device connected to the Internet.

${ }^{3}$ Tor does not protect traffic via other browsers.
} 
data, or to start using the peer-to-peer-based network Freenet (Gehl 2018; Graham and Pitman 2020). ${ }^{4}$

When engaging in educational activities online, we often automatically default to commercial applications without critically inquiring about data gathering and commodification strategies or other costs connected to the used products. Without much thought, we speak about 'skyping' with someone or about 'googling' a term. Thereby we implicitly naturalize the widespread use of particular commercial products and hide alternatives from view.

There are, however, always alternatives. For instance, the commercial programme Skype - since the Snowden revelations known to widely share all kinds of user-data with US secret services - can easily and efficiently be replaced with JitsiMeet - a non-commercial video-conferencing tool that is browser-based (i.e. it does not require installation), encrypts all communications by default, does not collect any user or connection data, and revokes all permissions granted (for use of camera and microphone) once the browser window it was used in is closed. Similarly, the noncommercial search engine DuckDuckGo enables web searches without tracking or data collection and does not individualize results in correspondence with user profiles. This, of course, leads to overall less relevant hits, but can enable access to information sources otherwise confined beyond the limits of specific filter-bubbles (Pariser 2011). Comparing search results acquired via Google with those reached via DuckDuckGo can be an interesting school exercise aimed at sensitizing learners for the contingencies of online search. These are just two among a plethora of other examples for readily available non-commercial products serving a variety of different purposes (see also Pötzsch 2019).

Protective add-ons, Tor, and alternative communication tools and search engines are not from the outset designed to serve educational purposes. However, through their non-commercial and privacy-enhancing nature, they constitute an important condition for critical and self-determined engagements with the Internet in educational and other settings. In addition, a defaulting of public institutions to free or donation-based services can save strained state budgets significant amounts of money and will lead to a gradual build-up of key technical expertise in-house

\footnotetext{
${ }^{4}$ For a list of trustworthy VPN providers, see: https://restoreprivacy.com/best-vpn/.
} 
(rather than relying on services from commercial actors). Therefore, an introduction of these alternative tools in schools is an important precondition for learners' ability to acquire autonomy and regain control about their online lives (Pötzsch 2019).

I will now move on to describe educational potentials of two specific noncommercial and collaborative software applications in more detail; 1 ) the online encyclopedia Wikipedia and 2) the free mobile game Phone Story (Molleindustria 2011).

\section{Wikipedia}

Wikipedia is an open collaborative online encyclopedia that is maintained by a community of volunteer editors and contributors. The site was launched in 2001 and is today ranked \#13 among the world's most frequented websites (2020). Wikipedia is operated by the Wikimedia Foundation a non-profit charity that bases its activities on donations. In 2018-19 the foundation had more than 350 paid employees and yearly expenses of roughly 90 million dollars (mostly used for salaries and wages). Among the most important donors are George Soros, Amazon, Facebook, and Google. ${ }^{5}$

Wikipedia is famous due to the fact that any visitor to any of the site's entries can access the page editor and freely add, delete, or change content (even without logging in or registering beforehand). This radical openness has caused wide-spread criticism concerning what is framed as a lack of quality control if 'anybody can edit' and has often been the reason for excluding the site from uses in schools and universities. ${ }^{6}$ However, Wikipedia offers a series of unique affordances that make it

${ }^{5}$ For updated numbers, see the entries 'Wikipedia' and 'Wikimedia Foundation' on Wikipedia.

${ }^{6}$ Due to the immense popularity of Wikipedia, some restrictions to content production have gradually been introduced from the 2010 s onward. For instance, today, only registered users can create new articles on the encyclopedia's English language edition and volunteer editors as well as a series of bots routinely patrol sites in all languages to prevent vandalism, sneak advertising, bullying, and propaganda. A series of articles about very contentious subjects had to be closed for free editing altogether with complaints and suggestions for changes delegated to the discussion pages of the concerned articles. 
very relevant for educational practices. The site makes possible a critical interrogation of, and conscientious participation in, the very processes of knowledge production that are usually eschewed in traditional encyclopedias. Therefore, the key question is not if one can use Wikipedia in teaching and learning, but how to use it properly to advance critical digital literacies.

As Hilde Brox (2012) among many others has argued, many pupils, students, and teachers regularly consult Wikipedia while at the same time assuming that the site 'should not really be used'. This reaction is based on a healthy skepticism regarding the knowledge conveyed by encyclopedias and other information sources; the only problem is that this critical sense usually remains limited to Wikipedia and is not extended to knowledge production in general. The almost complete transparency and participatory nature of Wikipedia, however, makes the site a prime tool for extending focus in precisely this manner.

Content on Wikipedia is presented on three different, yet related, layers; 1) the main article that constitutes the front stage of every entry and becomes accessible upon searching for a term; 2) the history pages behind the main article that make transparent every change that has ever been made to the article in question, and 3) discussion pages where specific themes or ideas relating to the subject can be posted and where contentious issues can be debated to avoid 'editing wars' - repeated editing back and forth between two or more opposing positions concerning a particular subject. Any visitor to any article on Wikipedia can freely (and anonymously) access all these features and edit the main article, visit the history pages, and follow and engage in debates on the discussion pages.

By for instance letting learners freely explore the possibilities of Wikipedia and later converge on collaborative development of specific subjectrelevant entries in class, pupils and students can be sensitized for Wikipedia's unique affordances and explore how these facilitate key elements of critical digital literacies; 1 ) open access to information via a freely accessible non-commercial site; 2) active participation in collaborative knowledge production; 3) transparency about the inherently historical nature of knowledge and the structures, actors, and processes behind its production; and 4) the ability to critically re-engage received forms of knowledge based on the acquired skills and insights. As Brox (2016) has shown, Wikipedia therefore readily lends itself to 
educational practices with an eye on fostering critical literacies and create awareness of important aspects of information management and participation in the contemporary digital era.

The next section will address how the material aspects of digital technologies highlighted earlier in the chapter can productively be taken up and worked with in educational practice. The freely accessible digital game Phone Story developed and disseminated by the Italian collective Molleindustria (2011) readily lends itself to such a purpose. ${ }^{7}$

\section{Phone Story}

Phone Story is a simple game that can be played on mobile and stationary devices. In a sequence of four consecutive skills-based challenges, players are led through the global production chain behind smart phones engaging in aspects of resource extraction, manufacture, use, and ewaste disposal. By these means, the game makes "the player symbolically complicit in coltan extraction in Congo, outsourced labor in China, ewaste in Pakistan, and gadget consumerism in the West" (Phone Story website). For teachers using the game in class, the Phone Story website contains information on each of the highlighted cases including links to reports or other resources about these issues. The website also contains a video walk-through enabling teachers to familiarize themselves with the entire game without having to play it through.

In schools where mobile devices are readily available among pupils, teachers can start lessons by asking the class to bring out their phones/tablets and download the game Phone Story. As an interesting result of this, users of Apple products such as iPhones or iPads will not be able to find the game in their app stores. The reason for this is that Phone Story has been banned from Apple stores due to its political content (Dredge 2011). The lesson can then commence with an exploration of new forms of censorship typical for a digital era and alert learners to the severe problems of invisibility in digital domains where marginalization and suppression of information is achieved through sorting algorithms that tacitly operate in the background.

\footnotetext{
${ }^{7}$ The game and supplementary materials can be accessed here: http://www.phonestory.org/
} 
Such initial rounds of reflection on new possibilities for censorship and control can then be followed up with a critical engagement with the aspects highlighted by the game's content. Limited sessions of individual or co-play can be followed up by teacher-led or pupil-driven activities where additional sources of information on the varied realities and implications of digital capitalism are identified and consulted. Subsequent debriefings can then focus on the quality of sources and the role of civil society organizations and trade unions in struggles against global exploitation and ecological degradation connected to the digital economy. By these means, play on devices familiar to most students can be used to highlight the severe social and environmental challenges connected to the production, sale, and use of these same technologies. Such a de-habitualisation of naturalized frames for perception and practice is a key condition for the acquisition of autonomy from within hegemonic orders (Freire 1970; Luke 2012).

\section{Critical Approaches to Hardware}

The global value chains and systems of exploitation of digital capitalism can also be interrogated in a practical hands-on approach to hardware products. One way is to bring broken computers, tablets, or smart phones to class and let learners freely explore the technology by opening up and gradually dismantling the devices. The overarching objective would be to assemble as much information as possible about the life cycles of specific products. Practical tasks can be to find and identify hardware components and trace their geographical origins in global manufacturing and dissemination chains or identify their potential future route across the globe as part of transnational streams of e-waste. Another might be to identify the natural resources required for the production of specific components, connect these to concrete extraction sites, and map local working conditions and environmental standards. It is important to note that in these exercises also the possible failure to acquire any relevant information can lead to important insights for instance regarding new forms of censorship (comparable to the erasure of the Phone Story game from Apple's app stores). The veiling of detrimental effects of established power relations is one prime strategy of maintaining hegemony, while learning to look through such techniques of power is a key element of critical literacies aimed at equipping learners with the resources and capabilities necessary to challenge and change unjust and oppressive conditions. 
The exercises described above require the availability of at least some functional digital tools in classrooms. In the last section of this chapter, I show briefly how critical digital literacies can be developed and conveyed without access to such technologies.

\section{Critical Digital Literacies Education in Low-Tech Classrooms}

Many aspects of the contemporary digital era can be critically interrogated in class without requiring the purchase of expensive new technologies or the acquisition of new skill sets by teachers and other educators (see also Simanowski 2018 and Pötzsch 2019). The development of critical digital literacies in non-digital educational settings can be achieved in a variety of manners, three of which are 1) the critical interrogation and historical contextualization of discourses about the digital including in the educational sphere, 2 ) in depth investigations of historical and contemporary cases with significance for a proper understanding and reflective use of digital technologies, and 3) the facilitation of practical political work by introducing various organisations working on issues of digital politics and economics including foundations, think tanks, trade unions, and civil society organizations. The three areas of inquiry are closely linked and can be made to complement one another in longer teaching sequences.

In sessions aiming at contextualizing prevalent technologies, teachers could for instance compare the campaigns of tobacco companies ('big tobacco') to suppress evidence of severe health-related implications of smoking with attempts by current era digital giants ('big tech') to avoid or down-play issues such as addiction to digital devices or the negative implications of commercial social media on mental health and democratic processes. One could also interrogate attempts to green-wash the digital industry through critical analysis of their marketing campaigns and the realities at production and extraction sites. Possible tasks could include asking what Facebook's tag line 'connecting people' means and contrasting this understanding with various alternative definitions of collectivity and sociality (see Fuchs 2017).

In a task most relevant for teacher students or advanced classes, one could critically interrogate policy documents and official reports about the need for digital technologies in classrooms. As among others Evgeny Morozov (2014) has noted, a specific form of public-private digital 'solutionism' is quick with prescribing costly solutions for ill-defined or 
plainly absent problems. Alerting learners to the politics and contingencies of public investments in educational and other technologies is an important endeavor that can be productively combined with exercises aimed at identifying non-commercial alternatives to the offered products. Through such analyses of discourses about the public acquisition of costly technologies, a complex interplay of a variety of state and private actors in the field of education can be brought to light (see Williamson 2015) and critically interrogated, before it can be contrasted with alternatives offered by civil-society organizations such as the Electronic Frontiers Foundation (EFF), Restore Privacy, Riseup.net, or the mostly Europe-based Chaos Computer Club (CCC). ${ }^{8}$

Lastly, traditional lectures in English literature or social studies can offer historical parallels to today's societies struggling with surveillance and increasing algorithmic control. One could re-read classics such as George Orwell's 1984 (1948) or Aldous Huxley's Brave New World (1932) and connect these works to discourses about digital politics and surveillance capitalism today. To what degree have todays socio-technical practices naturalized conditions of surveillance and control that appeared threatening and totalitarian in the mentioned novels? Literary and historical cases can then be brought into dialogue with contemporary works such as Dave Eggers's The Circle (2013), Laura Poitras's seminal documentary on Edward Snowden's NSA revelations Citizenfour (2014), the WikiLeaks revelations (Assange 2015, Harrison 2015), or artworks such as Trevor Paglen's Autonomy Cube. ${ }^{9}$

The examples offered above are just a few among a plethora of available critical works from fiction, documentary, activism, and art that can be used in largely non-digital classrooms to develop critical awareness and conscientious counter-practices. Theoretical endeavors of analyzing and contextualizing specific cases such as the NSA surveillance scandal (Poitras 2014; Stone 2016), the WikiLeaks revelations (Assange 2015, Harrison 2015) or the Cambridge Analytica affair (Amer and Noujaim 2019), and combining these with attention to similar literary themes or

\footnotetext{
${ }^{8}$ The mentioned organisations' websites can be accessed under the following links: https://www.eff.org/ (EFF), https://restoreprivacy.com/ (Restore Privacy), https://riseup.net/ (riseup.net), and https://www.ccc.de/en/ (CCC).

${ }^{9}$ More information on Paglen's Autonomy Cube can be found here: https://www.paglen.com/index.php?l=work\&s=cube
} 
historical precedents, invite critical reflections about learners' own life worlds and received practices, as well as the societal, economic and other structures that predispose these. Taken together, the suggested nondigital 'tools' (novels, documentaries, fiction films) can help to convey the critical (digital and other) literacies required to facilitate the maturation of today's young into reflected and autonomous democratic citizens.

\section{Conclusion}

This chapter has taken up the theme of critical digital literacies from both theoretical and applied vantage points. After summarizing key strains in thinking about various forms of literacy, I converged on the term critical digital literacies to grasp how contemporary education can respond to new technologies both in classrooms and beyond. Secondly, the chapter described some of the challenges connected to the digital era that are often under-emphasized in dominant discourses about digital literacy namely aspects of environmental and socio-political sustainability of the digital surveillance economy. Based on these conceptualizations, I made a series of suggestions on how such issues can be approached in various educational settings both with and without access to digital tools.

I hope that this chapter will inspire current and future teachers, learners, and others to critically engage the technologies that shape how we work, live and love, and how we see ourselves and each other. Such knowledge and awareness are key conditions for the formation of political alternatives aimed at shaping better, more just, more inclusive, and therefore, more sustainable futures.

\section{References}

Amer, K. \& Noujaim, J. (2019). The Great Hack. Los Gatos: Netflix.

Andrejevic, M. (2007). iSpy. Surveillance and Power in the Interactive Era. Lawrence: University Press of Kansas.

Assange, J. (2015). Introduction: WikiLeaks and Empire. In J. Assange (Ed.), The WikiLeaks Files: The World According to US Empire (pp. 1-19). London: Verso.

Ávila, JA. \& Zacher Pandya, J. (2013). Traveling, Textual Authority, and Transformation: An Introduction to Critical Digital Literacies. In JA. Ávila \& J. 
Zacher Pandya (Eds.), Critical Digital Literacies as Social Praxis: Intersections and Challenges (pp. 1-14). New York: Peter Lang.

Bayne, S. (2015). What's the Matter with Technology-Enhanced Learning? Learning, Media \& Technology, 40(1), 5-20.

Bigum, C. \& Rowan, L. (2015). Gorillas in Their Midst: Rethinking Educational Technology. In S. Bulfin, N.F. Johnson \& C. Bigum (Eds.), Critical Perspectives on Technology and Education (pp. 15-34). New York: Palgrave Macmillan.

Brox, H. (2012). The Elephant in the Room: A Place for Wikipedia in Higher Education? Nordlit, 30, 143-155.

Brox, H. (2016). Troublesome Tools: How Can Wikipedia Editing Enhance Student Teachers' Digital Skills? Acta Didactica Norden, 10(2), 329-346.

Barassi, V. (2016). Datafied Citizens? Social Media Activism, Digital Traces and the Question About Political Profiling. Communication and the Public, 1(4), 494499.

Buckingham, D. (1993a). Changing Literacies: Media Education and Modern Culture. London: Tufnell Press.

Buckingham, D. (1993b). Children Talking Television: The Making of Television Literacy. London: Falmer.

Buckingham, D. (2003). Media Education: Literacy, Learning and Contemporary Culture. Cambridge: Polity Press.

Buckingham, David. (2006). Defining Digital Literacy: What Do Young People Need to Know about Digital Media? Digital Kompetanse, 1(4), 263-276.

Cazden, C., Cope, B. Fairclough, N. \& Gee, J. (1996). A Pedagogy of Multiliteracies: Designing Social Futures. Harvard Educational Review, 66(1), 60-92.

Chinese Labour Watch. (2018). Amazon Profits from Secretly Oppressing its Suppliers' Workers: An Investigative Report on Hengyang Foxconn. http://www.chinalaborwatch.org/report/132

Curran, D. (2018). Are You Ready? Here Is All the Data Facebook and Google Have on You. The Guardian (March 30). 
https://www.theguardian.com/commentisfree/2018/mar/28/all-the-datafacebook-google-has-on-you-privacy

Dredge, S. (2011). Apple Bans Satirical iPhone Game Phone Story from its App Store. The Guardian Apps Blog (September 14). https://www.theguardian.com/technology/appsblog/2011/sep/14/applephone-story-rejection

Edwards, R. (2015). Software and the Hidden Curriculum in Digital Education. Pedagogy, Culture \& Society, 23(2), 265-279.

Eggers, D. (2013). The Circle. New York: Knopf Doubleday.

Fenton, N. (2016). Digital, Political, Radical. Cambridge: Polity Press.

Freire, P. (1970). Pedagogy of the Oppressed. New York: Continuum.

Fuchs, C. (2012a). Google Capitalism. TripleC: Communication, Capitalism \& Critique, 10(1), 42-48.

Fuchs, C. (2012b). The Political Economy of Privacy on Facebook. Television \& New Media, 13(2), 139-159.

Fuchs, C. (2017). Social Media: A Critical Introduction. London: Sage.

Gehl, R.W. (2014). Reverse Engineering Social Media: Software, Culture, and Political Economy in New Media Capitalism. Philadelphia: Temple University Press.

Gehl, R.W. (2015). The Case for Alternative Social Media. Social Media \& Society, July-December, 1-12. DOI: 10.1177/2056305115604338

Gehl, R.W. (2018). Weaving the Dark Web: Legitimacy on Freenet, Tor, and I2P. Cambridge: MIT Press.

Gehl, R.W. \& Synder-Yuly, J. (2016). The Need for Social Media Alternatives. Democratic Communiqué, 27, 78-82.

Gellman, B., Timberg, C. \& Rich, S. (2013). Secret NSA Documents Show Campaign Against Tor Encrypted Network. Washington Post, October 4. https://www.washingtonpost.com/world/national-security/secret-nsa- 
documents-show-campaign-against-tor-encrypted-

network/2013/10/04/610f08b6-2d05-11e3-8ade-a1f23cda135e story.html

Global E-Waste Monitor. (2017). http://ewastemonitor.info/

Golden, N.A. (2017). Critical Digital Literacies across Scales and beneath the Screen. Educational Media International, 54(4), 373-387.

Graham, R. \& Pitman, B. (2020). Freedom in the Wilderness: A Study of a Darknet Space. Convergence, 26(3), 593-619.

Gray, J., Gerlitz, C. \& Bounegru, L. (2018). Data Infrastructure Literacy. Big Data \& Society, 5(2). https://doi.org/10.1177/2053951718786316

Hagood, M. (2009). New Literacies Practices: Designing Literacy Learning. New York: Peter Lang.

Hall, S. (1977). Encoding/Decoding. In S. During (Ed.), The Cultural Studies Reader (pp. 91-103). London: Routledge.

Harcourt, B.E. (2015). Exposed: Desire and Disobedience in the Digital Age. Cambridge: Harvard University Press.

Harrison, S. (2015). Indexing the Empire. In J. Assange (Ed.), The WikiLeaks Files: The World According to US Empire (pp. 145-158). London: Verso.

Hinrichsen, J. \& Coombs, A. (2014). The Five Resources of Critical Digital Literacy: A Framework for Curriculum Integration. Research in Learning and Technology, 21(1). https://doi.org/10.3402/rlt.v21.21334

Hoechsmann, M. \& Poyntz, S.E. (2012). Media Literacies: A Critical Introduction. Chicester: Wiley-Blackwell.

Janks, H. (2009). Literacy and Power. London: Routledge.

Janks, H. (2014). The Importance of Critical Literacy. In J. Zacher Pandya \& JA. Ávila (Eds.), Moving Critical Literacies Forward: A New Look at Praxis Across Contexts (pp. 32-44). New York: Routledge.

Jenkins, H. (2006). Fans, Bloggers, and Gamers: Exploring Participatory Culture. New York: New York University Press. 
Jones, C. (2016). The Politics of Networked Learning. In T. Ryberg, C. Sinclaire, S. Bayne \& M. de Laat (Eds.), Research, Boundaries, and Politics in Networked Learning (pp. 59-74). Bern: Springer International Publishing.

Kellner, D. (1995). Media Culture: Cultural Studies, Identity and Politics Between the Modern and the Postmodern. London: Routledge.

Kitchin, R. \& Dodge, M. (2011). Code/Space: Software and Everyday Life. Cambridge: MIT Press.

Kress, G. (2003). Literacy in the New Media Age. London: Routledge.

Kress, G. \& Van Leeuwen, T. (2001). Multimodal Discourse: The Modes and Media of Contemporary Communication. London: Arnold.

Lankshear, C. \& Knobel, M. (2015). Digital Literacy and Digital Literacies: Policy, Pedagogy and Research Considerations for Education. Nordic Journal of Digital Literacy, 10(1), 8-20.

Lindh, M. \& Nolin, J. (2016). Information We Collect: Surveillance and Privacy in the Implementation of Google Apps for Education. European Educational Research Journal, 15(6), 644-663.

Livingstone, S. (2012). Critical Reflections on the Benefits of ICT in Education. Oxford Review of Education, 38(1), 9-24.

Luke, A. (2012). Critical Literacies: Foundational Notes. Theory into Practice, 51(1), 4-11.

Lynch, T.L. (2017). Below the Screen: Why Multiliteracies Research Needs to Embrace Software. English Journal, 106, 92-94.

Maxwell, R. \& Miller, T. (2012). Greening the Media. Oxford: Oxford University Press.

Mills, K.A. (2015). Literacy Theories for the Digital Age: Social, Critical, Multimodal, Spatial, Material and Sensory Lenses. Bristol: Multilingual Matters.

Morozov, E. (2014). To Save Everything, Click Here: The Folly of Technological Solutionism. New York: Ingram Publishers. 
Orlikowski, W.J. (2007). Sociomaterial Practices: Exploring Technology at Work. Organization Studies, 28(9), 1435-1448.

Pangrazio, L. (2016). Reconceptualising Critical Digital Literacy. Discourse: Studies in the Cultural Politics of Education, 37(2), 163-174.

Pangrazio, L. \& Selwyn, N. (2019). Personal Data Literacies: A Critical Literacies Approach to Enhancing Understandings of Personal Digital Data. New Media \& Society, 21(2), 419-437.

Pariser, E. (2011). The Filter Bubble. What the Internet is Hiding from Us. London: Penguin Books.

Poitras, L. (2014). Citizenfour. New York: Praxis Film.

Pötzsch, H. (2019). Critical Digital Literacy: Technology in Education Beyond Issues of User Competence and Labour-Market Qualifications. TripleC: Communication, Capitalism \& Critique, 17(2), 221-240.

Pötzsch, H. (2018). Archives and Identity in the Context of Social Media and Algorithmic Analytics: Towards an Understanding of iArchive and Predictive Retention. New Media \& Society, 20(9), 3304-3322.

Pötzsch, H. (2017). Media Matter. TripleC: Communication, Capitalism \& Critique, 15(1), 148-170.

Pötzsch, H. (2016). Materialist Perspectives on Digital Technologies: Informing Debates on Digital Literacy and Competence. Nordicom Review, 37(1), 119-132.

Qiu, J. (2016). Goodbye iSlave: A Manifesto for Digital Abolition. Urbana, IL: University of Illinois Press.

Qiu, J., Gregg, M. \& Crawford, K. (2014). Circuits of Labour: A Labour Theory of the iPhone Era. TripleC: Communication, Capitalism \& Critique, 12(2), 564-581.

Saariketo, M. (2014). Imagining Alternative Agency in Techno-Society: Outlining the Basis of Critical Technology Education. In L. Kramp (Ed.), Media Practice and Everyday Agency in Europe (pp. 129-138). Bremen: Edition Lumière.

Sandoval, M. \& Fuchs, C. (2010). Towards a Critical Theory of Alternative Media. Telematics \& Informatics, 27(2), 141-150. 
Santo, R. (2013). Hacker Literacies: User-Generated Resistance and Reconfiguration of Networked Publics. In JA. Ávila \& J. Zacher Pandya (Eds.), Critical Digital Literacies as Social Praxis: Intersections and Challenges (pp. 197217). New York: Peter Lang.

Schäfer, M.T. (2011). Bastard Culture! How User Participation Transforms Cultural Production. Amsterdam: Amsterdam UP.

Selwyn, N. (2016). Minding Our Language: Why Education and Technology Is Full of Bullshit... and What Might Be Done About It. Learning, Media \& Technology, 41(3), 437- 443.

Simanowski, R. (2018). Stumme Medien: Vom Verschwinden der Computer in Bildung und Gesellschaft. Berlin: Matthes \& Seitz.

Stone, O. (2016). Snowden. Los Angeles: Open Road Films.

Taylor, S. (2019). Is Tor Trustworthy and Safe? Restoreprivacy.com, October 29. https://restoreprivacy.com/tor/

Terranova, T. (2000). Free Labour: Producing Culture for the Digital Economy. Social Text, 18(2), 33-58.

Treré, E. (2016). The Dark Side of Digital Politics: Understanding the Algorithmic Manufacturing of Consent and the Hindering of Online Dissidence. IDS Bulletin: Transforming Development Knowledge, 47(1), 127-138.

Treré, E. (2018). From Digital Activism to Algorithmic Resistance. In G. Meikle (Ed.), The Routledge Companion to Media and Activism (pp. 367-375). London: Routledge.

Vuorikari, R., Punie, Y., Carretero, Y. \& van den Brande, L. (2016). Digi- Comp 2.0: The Digital Competence Framework for Citizens. Brussels: Joint Research Centre of the European Commission.

https://publications.jrc.ec.europa.eu/repository/bitstream/JRC101254/jrc101 254 digcomp $\% 202.0 \% 20$ the $\% 20$ digital\%20competence $\% 20$ framework\%20for \%20citizens.\%20update\%20phase\%201.pdf

Williamson, B. (2015). Governing Software: Networks, Databases and Algorithmic Power in the Digital Governance of Public Education. Learning, Media \& Technology, 40(1), 83- 105. 
Williamson, B. (2017). Big Data in Education: The Digital Future of Learning, Policy, and Practice. London: Sage.

Winner, L. (1980). Do Artifacts Have Politics? Daedalus, 109(1), 121-136.

Zuboff, S. (2019). The Age of Surveillance Capitalism: The Fight for a Human Future at the New Frontier of Power. London: Profile Books. 